\title{
14
}

\section{CONTINUING THE LEGACY AND BEGINNING A NEW ERA Australian nursing in the Korean War}

\author{
Rebecca Fleming
}

Reflecting on the influence of the Australian nursing sisters who served in the First World War, Major Dulcie Thompson, a veteran of the Second World War and the Korean War, explained the sense of legacy felt by those who followed the First World War sisters:

They came back and it was still very evident at the beginning of the Second World War that those women ... were something special and I think that helped them raise the status of civilian nursing ... But it was quite evident to us when we came into the army in the late 1930s and '40s that we had a great legacy from those women. ${ }^{1}$

As deputy matron in charge of Australian nurses at the British Commonwealth General Hospital (BCGH) in Kure, Japan, Thompson ensured that this legacy was inherited by nurses in the Korean War. As their predecessors had done, they carried out their work with a sense of professionalism, resourcefulness and dedication to the care of their patients. In many ways their experiences of war shared continuities with 
experiences of earlier conflicts. However, the Korean War also heralded an era of transition for Australian military nursing, and it is this balance of continuity and transition that is the focus here.

This chapter outlines the significance of the Korean War in the history of Australian military nursing, while highlighting the contribution made by Australian military nurses to that war. This contribution, although limited in numbers, was significant. The nominal roll of Australian veterans of the Korean War lists 34 Royal Australian Army Nursing Corps (RAANC) sisters and 21 Royal Australian Air Force Nursing Service (RAAFNS) sisters as serving in the Korean War between 1952 and 1956. ${ }^{2}$ But military nursing's contribution to the war went beyond that. The major support base and hospital for the British Commonwealth troops was at the BCGH in Kure, Japan, and that is where the majority of Australian army nurses were based. ${ }^{3}$ The army nursing staff there included trained nursing sisters, who were officers, and other-rank nursing assistants. The other ranks were formerly members of the Australian Army Medical Women's Services (AAMWS) staff who were incorporated into the military nursing hierarchy after the closure of the AAMWS when the army nursing service was made a corps in $1951 .{ }^{4}$

Not all of the army nurses stationed in Japan also served in Korea. The monthly reports for the BCGH in Japan included a nominal roll of staff, but there are gaps in the collection, as not all reports have survived. As a result, the exact number of army nurses who supported the Korean War from the BCGH in Japan is not known. However, an examination of BCGH reports reveals that more than 180 RAANC officers and other ranks served in Japan between 1951 and $1956 .{ }^{5}$ As the reports for 1950 are not available, the true figure is perhaps higher than 180 . Of these, 34 served in Korea, usually for two-month rotations. ${ }^{6}$ Combined with the 21 RAAFNS sisters, the records indicate that at least 201 Australian military nurses supported the Korean War in either Japan or Korea.

2 Nominal Roll of Australian veterans of the Korean War, nominal-rolls.dva.gov.au/.

3 H.C.H. Robertson to Secretary Chiefs of Staff Committee, 31 October 1951, British Korea Medal, MP927/1, A81/1/187, National Archives of Australia [NAA].

4 J. Bassett, Guns and Brooches: Australian Army Nursing from the Boer War to the GulfWar, Oxford University Press, Melbourne, 1997, p. 180.

5 British Commonwealth Base General Hospital, Army Component, 1950-56, AWM52, 11/2/45.

6 Betty Lawrence (née Crocker), interview with Rob Linn, 22 May 2002, J.D. Somerville Oral History Collection, OH 644/7, State Library of South Australia. 
The work carried out by nurses varied, depending on their location and service. At the BCGH in Kure, Australian nurses worked alongside British and Canadian nurses in an integrated hospital. ${ }^{7}$ The BCGH staff worked in medical and surgical wards as well as in theatre. ${ }^{8}$ Shifts mirrored those in the civilian sector, with the exception that staff stayed on duty to assist when convoys of patients arrived. ${ }^{9}$ Other ranks carried out nursing assistant duties, while sisters either were rostered on to manage the wards or assisted surgeons as theatre sisters. RAANC sister Betty Lawrence (née Crocker), who worked as a theatre sister, recalled that she was occasionally called on to complete sutures if the surgeons were called to a more urgent task. This kind of work was not normally assigned to nurses in the civilian sector. ${ }^{10}$

Injuries ranged from bullet and shrapnel wounds to abdominal wounds and frostbite, but the injuries that stood out for all the nurses were the severe burns, often the result of fires lit by soldiers in dugouts to keep warm in the freezing Korean winter. ${ }^{11}$ Dulcie Thompson recalled that these burns were so 'frightful' that she ensured nurses were not rostered to be with burns patients for long periods. ${ }^{12}$ Betty Hunt-Smith's recollection of treating one particular patient confirms the emotional difficulty for the nurses:

I had to deal with a patient and I walked towards him and I stopped, and I almost turned and walked out again, because he had been burnt by flamethrower, so that his entire face and his ears and hands were totally burnt. So I had to just pull myself together and go to him, talk to him. ${ }^{13}$

Duties at the British Commonwealth General Hospital occasionally extended beyond the hospital, with sisters being rostered onto convoy duty, which was rotated between the three Commonwealth nations. Convoy duty involved caring for patients in a train carriage as they were transported from Iwakuni airbase to the hospital in Kure. The journey was

7 Margaret (Peg) Webster (née Nicholson), interview with Jan Bassett, 3 November 1986, AWM S01820.

8 Colonel E.J. Bowe, visit to Japan, Korea and Hong Kong, 26 April to 31 May 1954, RAANC clothing in Korea, NAA, MP927, A61/1/55.

9 Margaret (Peg) Webster, interview.

10 Betty Lawrence, interview.

11 Barbara Probyn Smith, 'Sis', unpublished manuscript, PA Box 58 01/144, State Library of Victoria.

12 Dulcie Thompson, interview.

13 Betty Hunt Smith, interview with Bill Bunbury, 26 November 1998, AWM S01910. 
about 50 miles ( 80 kilometres), over which nurses did their best to ensure a smooth transition, and the comfort of patients, between the airbase and hospital. There were no doctors rostered to the convoy, so nurses were responsible for making key medical decisions during the trip and advising of medical and triage information at the handover. ${ }^{14}$

From September 1952, RAANC sisters were stationed in Korea for two-month rotations, working alongside Canadian and British nurses in the British Commonwealth Communications Zone Medical Unit (BCCZMU) in an old school house in the suburbs of Seoul, some 30 miles (48 kilometres) from the Korean front line. ${ }^{15}$ Conditions were difficult, and at first there was neither running water nor sheets for the beds. ${ }^{16}$ By 1955 running water had been installed on the top and ground floors, but water still had to be transported by buckets to the centre floor. ${ }^{17}$ The work at the BCCZMU was, as Lawrence described it, 'advanced first-aid'. ${ }^{18}$ As there were no facilities for surgery, the BCCZMU worked as a transit hospital in which patients were stabilised for the flight to Japan. ${ }^{19}$

Unlike the hospital duties carried out by RAANC nurses, the main role of RAAF sisters in the war was working on air evacuation flights. RAAFNS sisters worked on DC-3 Dakota aircraft. These planes were equipped to carry 24 litter patients or 27 walking patients, usually a combination of both. The Dakotas flew between the base at Iwakuni in Japan and Kimpo airbase near Seoul in Korea, where the casualties were picked up. The flight between Iwakuni and Kimpo took three to four hours. An RAAFNS sister and a male medical orderly accompanied all flights. ${ }^{20}$ As there were no doctors on board, the RAAF sister was responsible for the welfare of patients on the flight and had final say on whether or not the patients were to fly. ${ }^{21}$

14 E.J. McNair, A British Army Nurse in the Korean War: Shadows of the Far Forgotten, Tempus, Stroud, Gloucs, 2007, p. 141.

15 Bassett, Guns and Brooches, p. 183.

16 koreavets.tassie.net.au/espie.htm (site no longer exists).

17 Colonel E.J. Bowe, visit to Japan, Korea and Hong Kong.

18 Betty Lawrence, letter to Darryl McIntyre, in R. O'Neill, Australia in the Korean War 1950-1953,

vol. 2: Combat Operations, AWM \& AGPS, Canberra, 1985, p. 571.

19 Betty Lawrence, interview.

20 N.M. Kater, 'Air evacuation of casualties in the Korean War', Medical Journal of Australia, vol. 2, issue 3, 1953, p. 95.

21 Catherine Thompson (née Daniel), interview, 7 August 2007 (tape in possession of author). 
The RAAFNS sisters also accompanied patients between Japan and Australia, escorting Australian patients home. RAAFNS sisters would also occasionally accompany British patients as far as Singapore, where they would hand them over to British nursing sisters and enjoy some leave on the British base there. ${ }^{22}$ The flights to Australia were run fortnightly through Qantas. Escort duty to Australia was long, exhausting work for 27-30 hours of flying time; it was unlike anything that the nurses had performed in the civilian sector. ${ }^{23}$

In addition to flight duty, RAAFNS sisters staffed a holding ward at Iwakuni airbase. Here, they washed and fed incoming patients, attended to their dressings and administered any medication needed..$^{24}$ Their contact with the patients was transitional, the main priority being to facilitate the evacuation process.

In all, between February 1951, when the RAAF took over the evacuation of British Commonwealth casualties from Korea, and June 1956, when the last two RAAF sisters left Japan, RAAF sisters assisted in the evacuation of 14,924 casualties between Korea and Japan, 884 casualties between Japan and Australia, and 1,806 casualties between Japan and the United Kingdom. ${ }^{25}$

In many ways the experiences of the Korean War nurses mirrored experiences in earlier conflicts. Those who nursed at the BCCZMU in Korea faced the challenges of working with limited facilities and equipment. Perditta McCarthy recalled carrying out night rounds with the aid of a hurricane lamp ${ }^{26}$ — sisters of the Australian Army Nursing Service (AANS) had faced similar challenges on Lemnos in the First World War. ${ }^{27}$ Climate has often posed challenges for military nurses- the AANS sisters who served in the First World War faced extremes in climate, from the freezing winter in France to extreme heat in Egypt. ${ }^{28}$ Korea posed similar

22 Ibid.

23 No. 91 Composite Wing monthly medical report for August 1952, British Commonwealth Forces Korea, NAA, A705, 132/2/866.

24 Catherine Thompson, interview.

25 Report of medical section of RAAF transport flight for June 1956, British Commonwealth Forces Korea, NAA, A705, 132/2/866, Part 1.

26 R. Siers, 'Perditta McCarthy: A remarkable lady, with an indomitable spirit and a wonderful sense of humour', 15 March 2012, www.awm.gov.au/articles/blog/perditta-mccarthy-a-remarkablelady-with-an-indomitable-spirit-and-a-wonderful-sense-of-humour.

27 K. Harris, More Than Bombs and Bandages: Australian Army Nurses at Work in World War I, Big Sky Publishing, Sydney, 2011, p. 62.

28 Ibid., p. 69. 
challenges. Betty Lawrence recalled that the temperatures were so cold in Korea that sisters would carry penicillin in the pockets of their parkas to prevent the medication from freezing. ${ }^{29}$

In addition to nursing duties, some RAANC officers in Japan were also rostered on three-month rotations in the role of mess sister, during which they managed catering and events for the officers' mess. After managing functions ranging from social dinners to weddings, Nell Espie recalled that she felt like 'quite the caterer'. ${ }^{30}$ This role had also been carried out by AANS sisters during the First World War. ${ }^{31}$ In some ways, however, the Korean War signalled an era of transition for military nursing. The key transition in this period was mirrored in the broader Australian military: the increasing professionalisation of military nursing and a move towards career military nursing, rather than recruitment for the duration of a conflict.

A sign of these changes is evident in the motivations of the nurses who joined for the entire Korean War. The decisions of some nurses mirrored those of earlier generations of nurses and of other K Force volunteers. Richard Trembath identified five main motivations of $\mathrm{K}$ Force volunteers: a desire for adventure; career advancement; to combat communism; and the final two factors were linked-economic motivation and a feeling of what Trembath called 'restlessness' or social dislocation..$^{32}$ In line with other K Force volunteers, RAAF Sister Pamela Leahy cited the opportunity for adventure as one of the reasons for her enlistment, ${ }^{33}$ as had AANS sisters of the Second World War. ${ }^{34}$ RAAF sister Cathie Thompson (née Daniel) saw Korea as an opportunity to serve in war after having missed the chance to join during the Second World War, a motivation shared by some K Force volunteers. ${ }^{35}$

In some ways the motivations of Korean War nurses aligned with those of earlier generations, but it was the opportunity for career advancement that distinguishes some Korean War nurses from their predecessors.

29 Betty Lawrence, interview.

30 Nell Espie, interview, 5 December 2007 (tape in possession of author).

31 Harris, More Than Bombs and Bandages, p. 62.

32 R. Trembath, A Different Sort of War: Australians in Korea 1950-1953, Australian Scholarly Publishing, Melbourne, 2005, p. 97.

33 Department of Veterans' Affairs, Korea Biographies Official Veteran Representatives: 50th Anniversary 2001 Commemorative Mission, Department of Veterans' Affairs, Canberra, 2001, p. 28.

34 Bassett, Guns and Brooches, p. 114.

35 Catherine Thompson, interview, and Trembath, A Different Sort of War, p. 97. 
Betty Lawrence was reading through a newspaper on nightshift at Northfield Hospital in Adelaide when she noticed an advertisement recruiting nurses for $\mathrm{K}$ Force:

And at that time it was the end of the polio epidemic and I was just beginning to sort of think, what will I do now? And I don't know whether it was because of my father-I knew he'd been in the First World War but I hadn't heard much about it—or what, but I thought, 'Well, I've got the qualifications, I'll apply.' I felt that I was the sort of person they were looking for; I thought I'd be useful. ${ }^{36}$

In one sense these motivations clearly align with those of the male K Force volunteers, in that Lawrence saw joining the RAANC to serve in Korea as an opportunity for career advancement. However, in another sense the kind of career advancement being sought was quite distinct. As a trained nursing sister, Lawrence was seeking to advance her nursing career, not a career in the military. She also viewed her contribution to the war as that of a skilled career professional.

This emphasis on career advancement and travel were also themes drawn upon in the recruitment campaigns of the era. During the 1950s, the campaigns for the women's services adopted a new focus-not concentrating on service for a particular conflict, but rather promoting long-term career prospects. Career development was now promoted by the defence forces as a reason to join. This signalled a new era in military nursing, in which a permanent nursing service could now be seen as a long-term career for single women. Women were, however, still required to be discharged on marriage. ${ }^{37}$ Where recruitment campaigns of the Second World War called on women to 'join us in a victory job', campaigns in the Korean War era drew attention to opportunities for career advancement. ${ }^{38}$ One poster, aimed at recruiting other ranks nursing assistants, explicitly drew upon the legacy of army nursing but still used career opportunity as its key emphasis. ${ }^{39}$ The advertisement noted that no experience was needed and highlighted attractive pay and conditions,

36 Betty Lawrence, interview.

37 Pay and Allowances-Women's Services, memorandum, 29 August 1950, NAA, MP927/1, A247/1/38.

38 M. Oppenheimer, Australian Women and War, Department of Veterans' Affairs, Canberra, 2008, p.186.

39 Recruiting women's services including the Royal Australian Army Nursing Corps [RAANC] Women's Royal Australian Army Corps [WRAAC]—Women's Royal Australian Naval Service [WRANS]_Women's Royal Australian Air Force [WRAAF], NAA, B1552, 605. 
promoting the opportunity for a 'satisfying and rewarding career'. ${ }^{40}$ Another recruitment poster, aimed at officers, balanced traditional motivations for joining, including 'the prospect of adventure, travel, and advancement', with professional development opportunities, including 'post-graduate courses at the College of Nursing Australia [e.g. Tutor Sister] and participation in refresher courses in all branches of nursing. ${ }^{41}$ Neither poster was specifically targeted at recruitment for Korea, but both give an indication of the strong shift towards longer term career development and professionalisation.

Military nursing training during the Korean War also underwent a significant change, and it was through induction courses that a more militarised culture began to be introduced to Australian military nursing. Newly enlisted officers and other ranks were instructed in military discipline. Other ranks were also given training in basic nursing care. ${ }^{42}$ Betty Lawrence recalled that her training at the School of Army Health at Healesville, Victoria, included training in 'military discipline, military administration, military law, expected behaviour at military functions and of course parade ground drill and marching'. In addition, she explained, 'nursing officers were trained in procedures normally outside the range of civilian nurses such as suturing, intravenous transfusions, anaesthetic techniques, assessment and classification according to military rules of injuries, and transportation of wounded'. ${ }^{43}$ For some nurses who had joined the army before the Korean War, this new emphasis on military discipline was not a transition always openly embraced. Nancy Hummerston, for example, disliked the new rules requiring nurses to salute when they were not in indoor dress uniform: 'I didn't like all that. I used to avoid ... if there was a senior officer anywhere, hav[ing] to salute. ${ }^{34}$

The training for RAAFNS also changed during the Korean War era. In the Second World War, only an elite group of women were trained in medical air evacuation duties, as part of the Royal Australian Air Force Medical Air Evacuation Transport Unit. ${ }^{45}$ Following the remobilisation of the RAAFNS, the new training procedures incorporated air evacuation

40 Oppenheimer, Australian Women and War, p. 186.

41 Ibid.

42 'Initial Training-RAANC Ors CMF Block Syllabus of Training-12 months', Women's services-introduction of Women's Royal Australian Army Corps as staff officers, NAA, K1214/1, $241 / 1 / 018$.

43 Betty Lawrence to Darryl McIntyre, letter, 4 April 1982, AWM137.

44 Nancy Hummerston, interview, 6 December 2007 (tape in possession of author).

45 Oppenheimer, Australian Women and War, p. 102. 
training for all recruits. In addition to a three-week basic course, recruits undertook an aeromedical evacuation course, which included a demonstration of air-to-sea rescue, a dinghy drill and training flights. ${ }^{46}$ Unlike in the Second World War, all RAAF sisters deployed in Korea served on medical air evacuation duties, so the new emphasis on aeromedical evacuation in the training course reflected an expansion in the role of RAAF sisters as flight nurses.

Training for the deployed nurses also became more formalised, particularly for the other ranks, now formally part of the corps. A number of professional development initiatives were implemented at the BCGH in Kure, ranging from lectures and educational visits, to broader work opportunities such as working as an assistant in theatre. In her 1954 report of her visit to Japan and Korea, Matron-in-Chief Colonel Bowie noted the value of such an opportunity: 'At present one officer and one other-rank RAANC are included in the theatre team in order to gain more experience and training in this highly specialised work. ${ }^{37}$

Although the other ranks no doubt benefited from the increased professional development that came from being part of the corps, the change in status that came with moving from AAMWS to other ranks, which occurred while many were supporting the Korean War in Japan in 1951, caused some distress. Stationed in Japan as part of the AAMWS, the nurses had more or less been treated as officers, and when their status changed to other ranks they were no longer afforded this status. Dulcie Thompson, who was matron at the time, explained the challenge of this cultural change:

They were not allowed to come into the Officers' Club. My attitude was that I thought that you could have made an exception for the region, as long as the club changed their rules to let all or any of them come in. But the rule was that they could come in if they were invited and I thought that was not fair. Because there were some people who would be invited all the time and some who [would not] ... It was a difficult situation to resolve and nobody was very happy about it ... But as those people went home and the new ones came up they didn't really give much thought to it at all. ${ }^{48}$

46 E.J. Bowe and C. McRae, 'Nursing in the Australian military services', American Journal of Nursing, vol. 58 , no. 3, 1958, p. 379 .

47 Colonel E.J. Bowe, visit to Japan, Korea and Hong Kong.

48 Dulcie Thompson, interview. 
A key element that linked the Korean War nurses with earlier generations was their relationship with the wounded men. The nurses' accounts of their patients demonstrate the centrality of these men to their experience of war. While soldiers might recall the enemy, the landscape and the weapons, for nurses the central narrative of their stories is the patients and their wounds. Korean War nurses tended to refer to their patients as 'boys', as military nurses had done in earlier conflicts, often constructing the nurses' role in a maternal light. ${ }^{49}$ Marjorie Ford captured this spirit when she commented fondly that they were 'lovely boys ... Lovely young men. If you would've been their mother you would have been proud of them'. ${ }^{50}$ Ford not only referred to her patients as 'boys' but also explicitly adopted a maternal subjectivity when speaking of them. The nurses were sometimes older than their patients, but not usually old enough to be their mothers.

What stands out as unique among Korean War nurses is their fondness for their British patients. In earlier wars, Australian nurses tended to express a particular fondness for Australian patients. ${ }^{51}$ While Korean War nurses were equally fond of their Australian 'boys', the British patients held a special place in many of their hearts. The reason for this special relationship was that many of the British patients were national service conscripts and were often very young. RAANC other-rank Shirley McEwen explained her feelings on the issue:

You know when you get 18-year-olds in with some horrific wounds. I used to get on a bit of a soapbox about it. I couldn't change it. I couldn't fix it. But I could sound off about it. And we all did. We felt it quite strongly, most of us. ${ }^{52}$

The combination of youth and conscription greatly affected the nurses and foreshadowed political sentiments that would be expressed in Australia during the Vietnam War.

49 K. Holmes, 'Day mothers and night sisters: World War I nurses and sexuality', in Gender and War: Australians at War in the Twentieth Century, ed. J. Damousi and M. Lake, Cambridge University Press, Cambridge, 1995, p. 46.

50 Marjorie Ford, interview, 23 April 2008 (tape in possession of author).

51 In letters home, First World War Sister Narrelle Hobbes, for example, expressed a distinct preference for nursing Australian soldiers; see M. Oppenheimer, Oceans of Love, ABC, Sydney, 2006, p. 19.

52 Shirley Bennetts, interview with Bill Bunbury, 1998, AWM S01904. 
Australians served in the Korean War as part of the United Nations force. For RAANC nurses, this meant serving in an integrated hospital alongside British and Canadian nurses. In earlier conflicts, Australian nurses had worked with other nursing services, particularly the British, usually seconded from their own Australian units or having joined through the British military nursing system. Kirsty Harris has estimated that only 800 of the approximately 2,700 AANS personnel who served during the First World War did so in purely Australian units. ${ }^{53}$ The distinction in the Korean War was that Australian nurses served in an integrated force from the beginning.

For the most part, the records and reflections of the nurses suggest that this system worked well. The wards were set up so that each ward was staffed by a particular nursing service, while specialists and other medical staff were allocated from a different country. ${ }^{54}$ This ensured that the wards were not segregated by nationality and that nurses could work alongside colleagues who had been trained under the same system. Official reports and anecdotal evidence from the nurses emphasised that teamwork played a large role in the success of the unit.

As was the case in earlier wars, the Australian nurses felt that the British sisters adhered more closely to military rules. This occasionally frustrated the Australians, who considered themselves more practically focused. Nora Hayles recounted one story in which she was frustrated by the need to show deference to a British sister:

Now for instance I can remember one ward. The sister had taken her day off and there was an English sister there, and [we] had a patient who had put in for a leave pass. He was on a strict diet, mind you, and he'd asked for a day's leave pass. And I said, 'You better get the major to either cancel his diet or cancel his pass.' 'Oh,' she said. 'Oh no, I couldn't ask him that.' ... I don't say they're all like that, but this one ... couldn't ask them to change anything. ${ }^{55}$

53 K. Harris, 'Red rag to a British bull? Australian trained nurses working with British nurses during World War One', in Exploring the British World: Identity, Cultural Production, Institutions, ed. K. Darian Smith, P. Grimshaw, K. Lindsey and S. Macintyre, RMIT Publishing, Melbourne, 2004, p. 126.

54 N.C. Davis, 'Surgical aspects of the Korean War, March 1951 to February 1952', Medical Journal of Australia, vol. 2, issue 11, 1952, p. 372.

55 Nora Trethewie (née Hayles), interview with Jan Bassett, 23 May 1987, AWM S01809. 
Although the Korean War represented a shift towards a more militarised culture in army nursing, this story illustrates that Australian nurses were not completely absorbed into a military culture; they still valued their practicality.

Another key aspect of the Korean War that embodied a change in military nursing was that many of the nurses were or would become veterans of more than one war. The Australian nurses who served in Korea were a combination of newly recruited members and veterans of the Second World War, as was the case with the broader K Force contingent. The RAAFNS in particular benefited from the experiences of women with experience of a previous war, such as Helen Cleary, Lucy Marshall and Phyllis Scholz, who had undertaken pioneering aeromedical evacuation work in New Guinea during the Second World War. These veterans now served in Korea, mentoring new members. ${ }^{56}$ Cathie Thompson, who enlisted in the RAAFNS for the Korean War, fondly recalled working with Helen Cleary, a more experienced nurse, and admired the work she had done in Singapore. She recalled that Cleary had lots of tales, some sad and others funny. ${ }^{57}$ As the Korean War came so soon after the Second World War, it gave the opportunity for new nurses to learn directly from those with conflict experience.

Many of the RAAF sisters who served in Korea went on to have significant military careers. For example, Helen Cleary had joined the RAAFNS in 1943 and was one of the earliest members to be involved in medical air evacuation duties, serving in New Guinea, Borneo and Singapore in the evacuation of prisoners of war, as well as teaching the first Australian postwar medical air evacuation course. From 1952 until mid-1953 she was the senior sister at Iwakuni. After the war she continued a career in the RAAFNS, reaching the position of matron-in-chief in 1967 and retiring from that position and the RAAFNS in $1969 . .^{8}$ RAAFNS sisters Betty Bristow Docker and Betty Edwards, who both also rose to the position of matron-in-chief, had also served in Japan and Korea. ${ }^{59}$

56 'Brief on nursing career in RAAFNS', in O'Neill, Combat Operations, p. 582, and RAAFNS historical events photographs and news items (scrapbook), 1940-64, part 3, AWM137, 3/3.

57 Catherine Thompson, interview.

58 G. Halstead, Story of the RAAF Nursing Service, 1940-1990, Nungurner Press, Metung, Vic, 1994, pp. 381-4.

59 Ibid., pp. 385-402. 
A number of RAANC officers who served in Korea also went on to have distinguished military careers. Two examples are Nell Espie and Perditta McCarthy. Espie joined the corps in July 1951 and served in Japan and Korea from July 1952 until April 1954. Following the Korean War, she built a successful military nursing career, serving in Malaya and Vietnam and culminating her service with an appointment to lieutenant colonel and matron-in-chief of the RAANC in January $1971 .^{60}$ The creation of the RAANC in 1951, together with the new emphasis on career within the RAANC, was a major shift in the conception of the role of Australian military nurses. Espie was one of the first career military nurses. Her fellow Korean War RAANC officer, Perditta McCarthy, who had also served in Papua New Guinea and with the British Commonwealth Occupation Force in postwar Japan, was the first Australian army nurse to be promoted to the rank of brigadier. ${ }^{61}$

Of course, not all the nurses who served in Korea continued a military nursing career. Some married and raised families, others pursued civilian nursing careers. For some, such as Nora Hayles, a career in the army in a period of peace did not offer the same challenges as wartime nursing. After returning from Japan, Hayles worked at a camp hospital at Puckapunyal, caring for national servicemen. The nursing work was quite different from that which she had undertaken in Japan. She recalled that it was mostly medical, with little surgical work. The lack of surgical work apparently influenced her decision to leave the army, saying that she left because 'there wasn't the work to do'. ${ }^{62}$ So although military nursing was increasingly being promoted as a long-term career during this period, it did not necessarily offer the challenges associated with nursing in a war zone.

On her return from Korea, RAANC sister Dorothy Wheatley stayed in the corps to develop her interest in nursing education, which she had developed by working with United States Army nurses in Korea. While still in the army, Wheatley completed a Diploma in Education at the Royal College of Nursing, Australia, then went on to work at the School of Army Health at Healesville, Victoria. After 10 years with the RAANC, she decided it was time to move on. She met a former colleague who offered her a position as a nurse educator at Sir Charles Gairdner Hospital

60 Espie, Nellie Jane, NAA, B2458, F64.

61 Oppenheimer, Australian Women and War, p. 189.

62 Nora Trethewie, interview. 
in Perth. For the next 25 years this position provided her the opportunity to pursue her passion for nursing education. During her time at the hospital she was involved in the transfer of nursing training from hospitals to a university-based system, and she retired when the last hospital-based school closed. ${ }^{63}$ Wheatley's nursing career from the Korean War onwards was focused on the change to the university-based system, which she had admired while working with American nurses during the war. Although she did not remain in the RAANC, Wheatley's experiences in the Korean War were clearly influential in her later nursing career.

For women such as Shirley Bennetts (née McEwen), the connections made with the patients they nursed influenced their personal and political views. Reflecting on how she was changed by the war, Bennetts said:

I think growing up during the war, I thought to go and fight for your country was a very brave heroic wonderful thing, but by the time I got up there and saw what it was, I didn't think it was quite so good ... Seeing these young men. Seeing the injuries, the burns, the amputations, from treading on landmines. And I just thought, what a waste of young men. ${ }^{64}$

The Korean War undoubtedly changed the lives of all who were touched by it, and the Australian Korean War nurses were no exception.

63 Dorothy Wheatley, interview, 7 January 2008 (tape in possession of author).

64 Shirley Bennetts, interview. 
This text is taken from In from the Cold: Reflections on Australia's Korean War, edited by John Blaxland, Michael Kelly and Liam Brewin Higgins, published 2020 by ANU Press, The Australian National University, Canberra, Australia. doi.org/10.22459/IFTC.2019.14 